\title{
\begin{tabular}{|l|l|l|l|l|}
\hline $\mathrm{M}$ & $\mathrm{R}$ & $\mathrm{S}$ & Internet Journal of & Nitride Semiconductor Research \\
\hline
\end{tabular}
}

Volume 1, Article 45

\section{GaN Layers Grown by HVPE on P-type 6H-SiC Substrates}

\author{
A.E. Nikolaev, Yu.V. Melnik, M.N. Blashenkov, N.I. Kuznetsov, I.P. Nikitina, A.S. Zubrilov, D.V. Tsvetkov \\ Cree Research EED \\ and \\ loffe Physical-Technical Institute \\ V. I. Nikolaev, V.A. Dmitriev, V.A. Soloviev \\ loffe Physical-Technical Institute
}

This article was received on June 2, 1996 and accepted on December 19, 1996.

\begin{abstract}
Gallium nitride films were successfully grown by HVPE technique on p-type $6 \mathrm{H}-\mathrm{SiC}$ substrate. The layers exhibit high crystal quality as was determined by X-ray diffraction. Photoluminescence (PL) of these films was measured. The PL spectra were dominated by band edge emission. Concentration $N_{d}-N_{a}$ in undoped epitaxial layers ranged from $2 \times 10^{17}$ to $1 \times 10^{19} \mathrm{~cm}^{-3}$. Mesa-structures formed by reactive ion etching showed good rectifying current-voltage characteristics for $\mathrm{GaN} / \mathrm{SiC}$ pn heterojunctions.
\end{abstract}

\section{Introduction}

\subsection{HVPE Advantages}

The HVPE method is a promising technique for deposition of thick GaN single crystal layers. The main advantages of this method are high growth rate and low cost. Recent progress in HVPE growth shows that high quality GaN layers can be obtained [1] [2] [3]. The crystalline, electrical and optical properties of these films are comparable with the best characteristics reported in the literature for GaN produced by MOCVD [4] [5] and MBE [6] [7].

Besides, HVPE allows one to grow high quality GaN layers on SiC substrates without any buffer layer [1]. This feature is important for producing electronic devices with vertical geometry.

\subsection{GaN/SiC Heterodevices}

The direct deposition of $\mathrm{GaN}$ on $\mathrm{SiC}$ also provides one the opportunity to create devices based on $\mathrm{GaN} / \mathrm{SiC}$ heterojunctions (e.g. heterojunction bipolar transistor) [8] [9]. Recently p-GaN on n-SiC has been successful grown by MBE and junction characteristics have been achieved. [10].

\subsection{Alternative to Ohmic Contact to $p-G a N ?$}

One of the obstacles in GaN device fabrication is the absence of a suitable ohmic contact to $p$-GaN. To overcome this problem, the inverse $\mathrm{GaN}$ device structure i.e. $\mathrm{pSiC}$ (substrate)/pGaN/.../nGaN may be used. The best ohmic contact to $p-G a N ~[11]$ has a resistivity about 3 orders of magnitude higher than that for $n-G a N$ [11] [12] and about 2 orders of magnitude higher than that for $\mathrm{p}$-SiC [13]. A large area $\mathrm{p}$-contact to $\mathrm{SiC}$ will contribute negligibly to the overall device series resistance. However to the best of our knowledge there are no reports on growth $\mathrm{GaN}$ on p-type SiC substrates.

In this paper we report on properties of $n$-GaN layers grown by HVPE directly on $\mathrm{p}$-type SiC substrates. Preliminary result on $\mathrm{n}-\mathrm{GaN} / \mathrm{p}-\mathrm{SiC}$ heterojunction are presented. 


\section{Experiments}

\subsection{GaN Epitaxial Growth}

GaN n-type layers were grown by HVPE on p-type $6 \mathrm{H}-\mathrm{SiC}$ manufactured by Cree Research, Inc. The $\mathrm{N}_{\mathrm{d}}-\mathrm{N}_{\mathrm{a}}$ concentration in the wafers was about $1 \times 10^{18} \mathrm{~cm}^{-3}$. The layers were deposited on the on-axis (0001)Si face of the substrates. A hot-wall open flow reactor was employed. $\mathrm{HCl}$ was reacted with liquid $\mathrm{Ga}$ to form $\mathrm{GaCl}$ gas which was transported to the growth zone where it was reacted with $\mathrm{NH}_{3}$ resulting in $\mathrm{GaN}$ deposition on the $\mathrm{SiC}$ substrate. The thickness of the GaN layers ranged from 0.5 to $2 \mu \mathrm{m}$. The GaN growth rate was controlled from 0.02 to $0.4 \mu \mathrm{m} / \mathrm{min}$

\subsection{Mesa-structure and Contacts}

Mesa-structures (150 $\mu \mathrm{m}$ diameter) were formed by reactive ion etching [14] using dichlor-difluoromethane $\left(\mathrm{CCl}_{2} \mathrm{~F}\right.$ 2). Two kind of metal compositions were used as ohmic contacts to $n-G a N$. They were Ti/Ni contacts annealed at $1000^{\circ} \mathrm{C}$ [11] and as deposited Al contacts (for GaN films with $\mathrm{N}_{\mathrm{d}^{-}} \mathrm{N}_{\mathrm{a}}>10^{18} \mathrm{~cm}^{-3}$ ). Both of them were used as a mask for $\mathrm{GaN}$ plasma etching. Al or In were used as a backside contact to $\mathrm{SiC}$ substrate.

\subsection{Investigation}

The layers were characterized using x-ray diffraction. Capacitance- voltage measurements were performed employing a Hg-probe. Luminescent properties of the GaN layers were also examined. Current-voltage and capacitance-voltage characteristics of mesa-structures were investigated. Electron beam induced current (EBIC) and back scattered electron (BSE) techniques were used to study GaN/SiC heterojunction.

\section{Results}

\subsection{Crystal quality}

The GaN layers was a smooth over the entire wafer. The full width at half maximum (FWHM) of double crystal x-ray $\omega$-scan rocking curves (RC) for (0002) GaN reflection ranged from 120 to 700 arcsec (Figure 1). It was found that the FWHM of RC's for $\omega$-scan are much larger than FWHM for $\omega, 2 \Theta$-scan. This feature of the x-ray RC is similar to RC characteristic obtained for $\mathrm{GaN}$ grown on $\mathrm{n}-6 \mathrm{H}-\mathrm{SiC}$ substrates [l]. It may be proposed that in both cases the dislocation distribution in the epitaxial layers is between an uniform distribution and a block-mosaic structure where blocks of the material having low dislocation density are separated from one another by dislocation boundaries. It was found that there are rather large residual thermal strains in GaN layers. If the thickness of the layer exceeds $1.5 \mu \mathrm{m}$ cracks formation is observed.

It must be pointed out that the crystal quality of the epitaxial layer strongly depends on the substrate quality (Figure 1). It was found that the crystal quality of GaN films grown on n-type $\mathrm{SiC}$ at the same growth conditions is better than those grown on $\mathrm{p}$-type SiC. This fact may be associated with difference in crystal quality of used SiC wafers. The FWHM of RC's of n-type SiC wafers is less than that of p-type SiC wafers. Detailed study of substrate crystal quality effect on GaN structural perfection will be published elsewhere. [15]

\subsection{Luminescence}

The GaN layers were characterized by photoluminescence (PL) at 80 and $300 \mathrm{~K}$. The PL experiments were performed using a pulsed nitrogen laser with a peak power of $2 \mathrm{~kW}$. The PL spectra (Figure 2,3) showed a sharp ultraviolet peak centered at $\sim 361 \mathrm{~nm}(80 \mathrm{~K})$, with the FWHM of $\sim 4 \mathrm{~nm}(37 \mathrm{meV})$. At $300 \mathrm{~K}$ the FWHM was $\sim 8 \mathrm{~nm}$ (72 meV). Some samples exhibited a strong blue luminescence band at $430-450 \mathrm{~nm}$ which may be attributed to structural defects or autodoped impurities.

\subsection{Electrical properties}

$\mathrm{N}_{\mathrm{d}}-\mathrm{N}_{\mathrm{a}}$ concentration in the $\mathrm{n}-\mathrm{GaN}$ layers was measured to be the range from $2 \times 10^{17}$ to $1 \times 10^{19} \mathrm{~cm}^{-3}$. It was found 
that the background concentration depends on crystal quality of the GaN layer. We may assume that high donor concentration is caused by some kind of structural defects in GaN layer.

\subsection{Electrical properties of mesa-structures}

The capacitance-voltage ( $\mathrm{C}-\mathrm{V})$ characteristics of the $\mathrm{GaN} / \mathrm{SiC}$ pn heterojunctions measured at frequencies of $10 \mathrm{kHz}$ and $1 \mathrm{MHz}$ were linear when plotted in $\mathrm{C}^{-2.5} \mathrm{-V}$ coordinates (Figure 4), which is typical for an anisotype heterojunctions with high densities of interface states. The cut-off voltage was about $2.02 \mathrm{~V}$ at $1 \mathrm{MHz}$ and about $2.08 \mathrm{~V}$ at $10 \mathrm{kHz}$. This value is close to the built-in potential for $\mathrm{n}-\mathrm{GaN} / \mathrm{p}-6 \mathrm{H}-\mathrm{SiC}$ heterojunction estimated using Anderson's model to be $2.17 \mathrm{~V}$ [16].

The structures showed good rectifying characteristics for $\mathrm{GaN} / \mathrm{SiC}$ pn heterojunctions. (Figure 5) Breakdown voltages is ranged from 15 to $100 \mathrm{~V}$. The turn-on voltage for forward I-V characteristic was $\sim 2 \mathrm{~V}$ which corresponds to build-in potential of the heterojunction. (Figure $5 \mathrm{a}$ ) It should be note that the value of cut-off voltage determined from $\mathrm{C}-\mathrm{V}$ measurements is closed to the turn on voltage for forward I-V characteristics. Detail study of electrical characteristics of the $\mathrm{GaN} / \mathrm{SiC}$ heterojunction, influence of interface on electrical properties and the theoretical calculation for the bandgap diagram will be published [16].

A weak electroluminesence (EL) was detected in some samples at room temperature. The EL was dark red when a forward voltage was applied and white-blue under reverse bias.

\subsection{EBIC}

The location of heterojunction inside the structures was determined by simultaneous detection of EBIC and BSE signals by scanning electron probe on the cleaved structure. Figure 6 shows BSE and EBIC signal profiles across an $\mathrm{GaN} / \mathrm{SiC}$ heterostructure. As known, EBIC curve maximum corresponds to the middle of the space charge region. In the investigated structures a shift of EBIC signal maximum from the GaN/SiC interface to SiC was observed. The shift value was about $0.03 \mu \mathrm{m}$. This value is close to half of the space charge region width at zero bias of $0.06 \mu \mathrm{m}$ determined by $\mathrm{C}-\mathrm{V}$ measurements.

\section{Summary}

Gallium nitride films have been successfully grown on $\mathrm{SiC}$ by HVPE technique. For the first time, $\mathrm{p}$-type $6 \mathrm{H}-\mathrm{SiC}$ wafers were used as substrates for GaN deposition. The layers exhibit high crystal quality as was determined by X-ray diffraction. The FWHM for the $\omega$-scan rocking curve for (0002) GaN reflection was $\sim 120$ arcsec. The photoluminescence spectra for these films were dominated by band edge emission. The FWHM of the edge PL peak was about $37 \mathrm{meV}$ at $80 \mathrm{~K}$. The minimum $\mathrm{N}_{\mathrm{d}}-\mathrm{N}_{\mathrm{a}}$ concentration in undoped layers was $2 \times 10^{17} \mathrm{~cm}^{-3}$.

Mesa-structures were formed by reactive ion etching. GaN/SiC pn heterojunctions showed good rectifying characteristics. The value of cut-off voltage determined from $\mathrm{C}-\mathrm{V}$ and I-V measurements was about $2 \mathrm{~V}$. This value is close to the built-in potential estimated by Anderson's model for $6 \mathrm{H}-\mathrm{SiC} / \mathrm{GaN}$ heterojunctions. EBIC study showed that the space charge region of the heterojunction is shifted towards the $\mathrm{SiC}$ substrate.

\section{Acknowledgments}

The authors are grateful to K. V. Vassilevski, E. V. Kalinina, V. E. Sizov and M. V. Rastegaeva for a mesa-structures preparation. The special thanks to K. V. Vassilevski for useful discussions. This work was supported in part by Russian Foundation of Fundamental Researches (contract number 95-02-04148-a).

\section{References}

[1] YuV Melnik, IP Nikitina, AS Zubrilov, AA Sitnikova, YuG Musikhin, VA Dmitriev, Inst. Phys. Conf. Ser. 142, 863-866 (1996).

[2] R. J. Molnar, R. Aggarwal, Z. L. Liau, E. R. Brown, I. Melngailis, W. Gütz, L. T. Romano, N. M. Johnson, Mater. Res. Soc. Symp. Proc. 395, 189-194 (1996). 
[3] K. Naniwae, S. Itoh, H. Amano, K. Itoh, K. Hiramatsu, I. Akasaki, J. Cryst. Growth 99, 381 (1990).

[4] IP Nikitina, VA Dmitriev, Inst. Phys. Conf. Ser. 141, 431-436 (1995).

[5] T. Warren Weeks, Michael D. Bremser, K. Shawn Ailey, Eric Carlson, William G. Perry, Robert F. Davis, Appl. Phys. Lett. 67, 401-403 (1995).

[6] TD Moustakas, RP Vaudo, R Singh, D Korakakis, M Misra, A Sampath, ID Goepfert, Inst. Phys. Conf. Ser. 142, 833-838 (1996).

[7] M. E. Lin, S. Strite, A. Agarwal, A. Salvador, G. L. Zhou, N. Teraguchi, A. Rockett, H. Morkoc, Appl. Phys. Lett. 62, 702-704 (1993).

[8] JI Pankove, SS Chang, HC Lee, RJ Molnar, TD Moustakas, B Van Zeghbroeckin Proc. of IEDM 94, , (1994) 389.

[9] J. I. Pankove, M. Leksono, S. S. Chang, C. Walker, B. Van Zeghbroeck, MRS Internet J. Nitride Semicond. Res. 1, 39 (1996).

[10] D Korakakis, A Sampath, ID Goepfert, TD Moustakas, Mater. Res. Soc. Symp. Proc. 395, 151-156 (1996).

[11] K.V. Vassilevski, M.G. Rastegaeva, A.I. Babanin, I.P. Nikitina, V.A. Dmitriev, MRS Internet J. Nitride Semicond. Res. 1, 38 (1996).

[12] M. E. Lin, Z. Ma, F. Y. Huang, Z. F. Fan, L. H. Allen, H. Morkoc, Appl. Phys. Lett. 64, 1003-1005 (1994).

[13] MG Rastegaeva, AN Andreev, VE Chelnokov, KV Vassilevski, AI Babanin, IP Nikitina, AA Lavrent'ev, in Int. Seminar Semiconductor Silicon Carbide and SiC-Based Devices, Book of of Abstracts, Edited by: VE Udaltsov, (Novgorod State University, Novgorod, 1995) 50-52.

[14] KV Vassilevski, VE Sizov, Al Babanin, YuV Melnik, AS Zubrilov, Inst. Phys. Conf. Ser. 142, 1027-1030 (1996).

[15] YuV Melnik, IP Nikitina, AE Nikolaev, DV Tsvetkov, AA Sitnikova, VA Dmitriev, unpublished (1996).

[16] NI Kuznetsov, AE Gubenco, AE Nikolaev, YuV Melnik, MN Blashenkov, IP Nikitina, VA Dmitriev, Mater. Sci.

Eng. B 46, 74-78 (1997). 

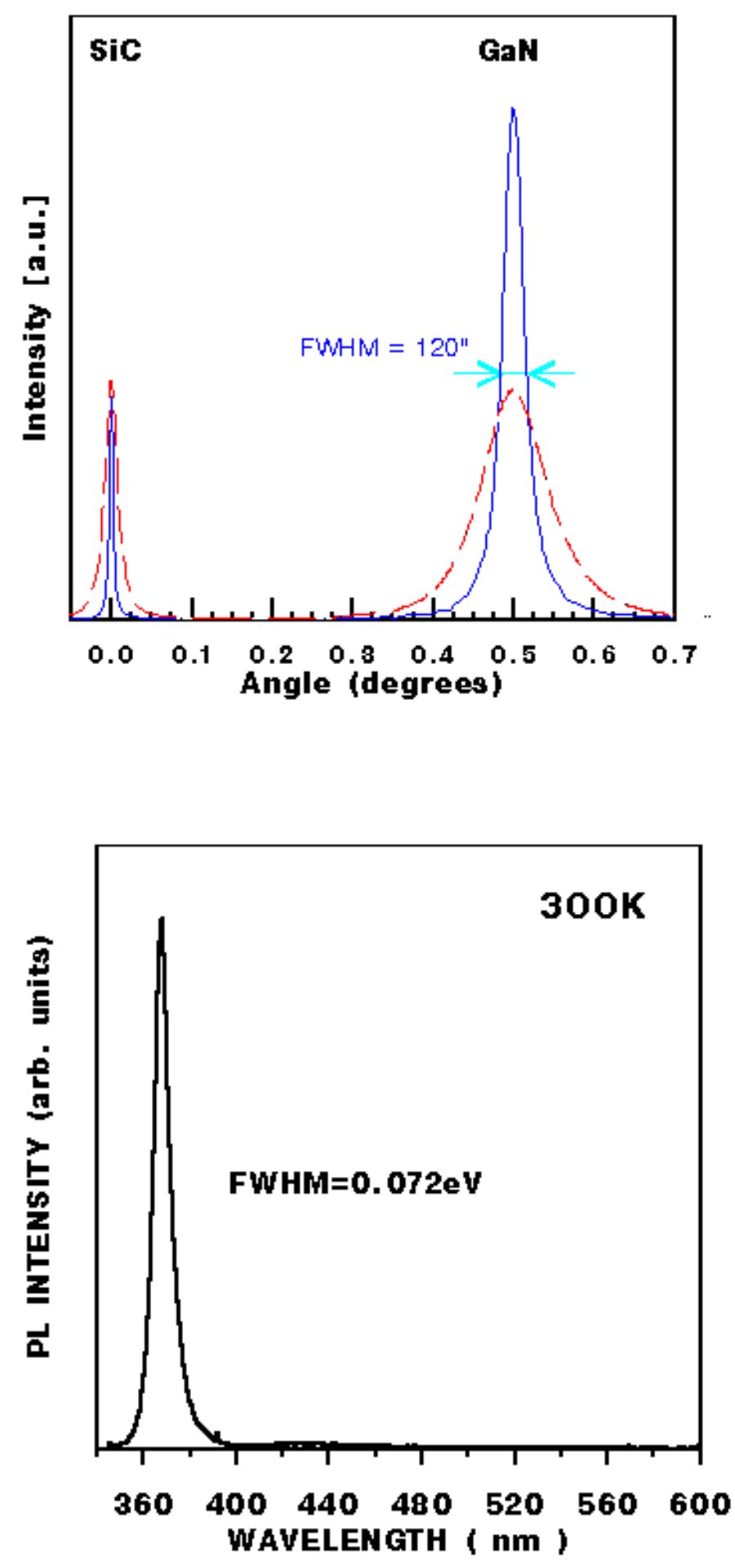

Figure 1. X-ray $\omega$-scan rocking curves for $\mathrm{GaN}$ layers grown on different substrate. The blue line represents $\mathrm{RC}$ for best $\mathrm{GaN}$ layer grown on $\mathrm{p}-6 \mathrm{H}-\mathrm{SiC}$ substrate. The FWHM of peak from substrate is 24 arcsec. This value is significantly less than 65 typical for used substrates. The RC for GaN layer on convinient substrate is presented by red line.
Figure 2. Room temperature PL spectrum for GaN layer. 

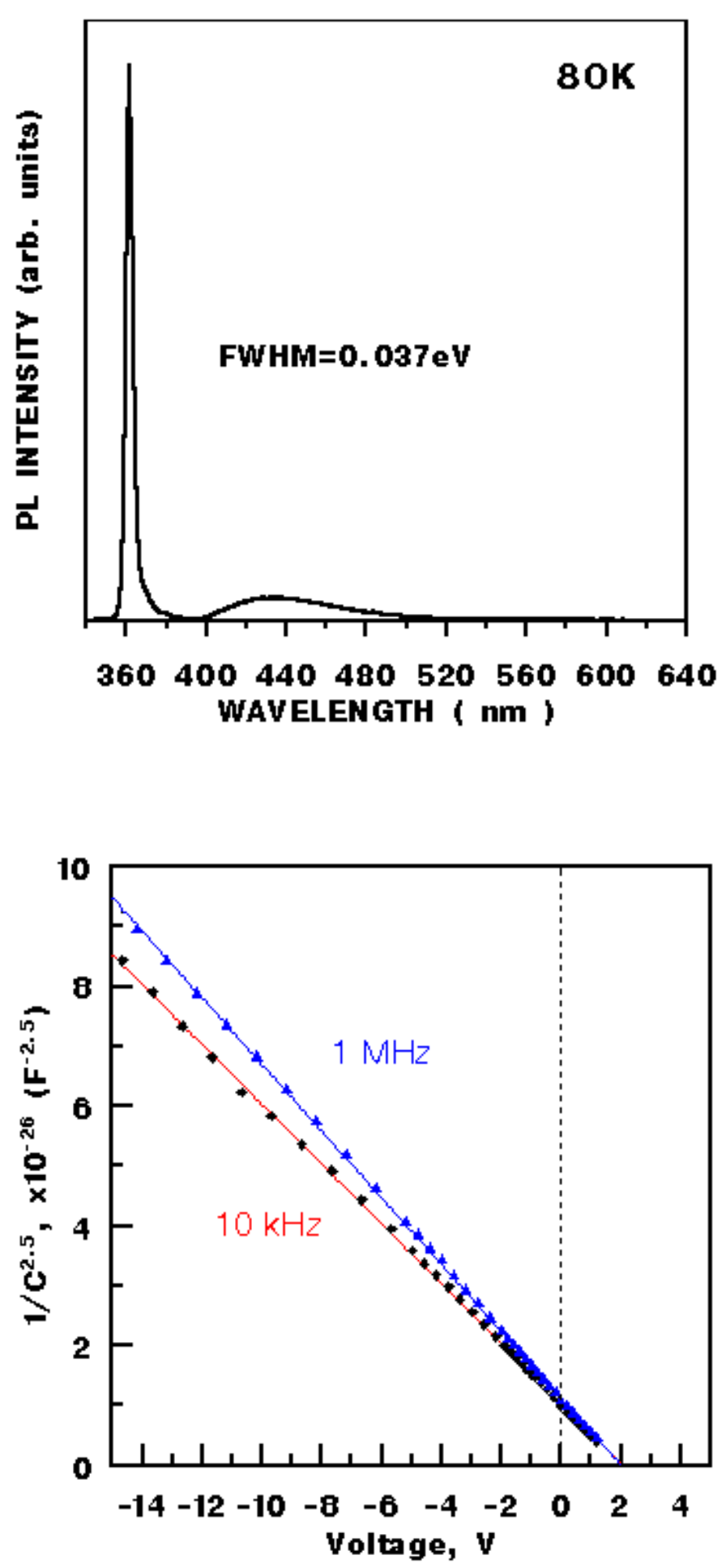

Figure 3. $\mathrm{PL}$ spectrum for $\mathrm{GaN}$ layer at $\mathrm{T}=80 \mathrm{~K}$.
Figure 4. The capacitance-voltage characteristics of the $\mathrm{GaN} / \mathrm{SiC}$ pn heterojunctions measured at frequencies of $10 \mathrm{kHz}$ (red-solid line) and $1 \mathrm{MHz}$ (blue-dashed line). 


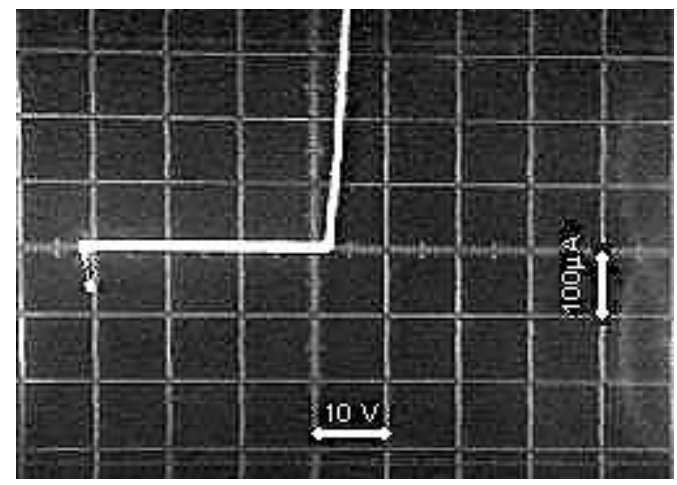

Figure 5. Current-voltage characteristic of $\mathrm{n}-\mathrm{GaN} / \mathrm{p}-\mathrm{SiC}$ heterojunction diode (vertical scale - $100 \mu \mathrm{A} / \mathrm{div}$, horizontal scale- $10 \mathrm{~V} / \mathrm{div})$.

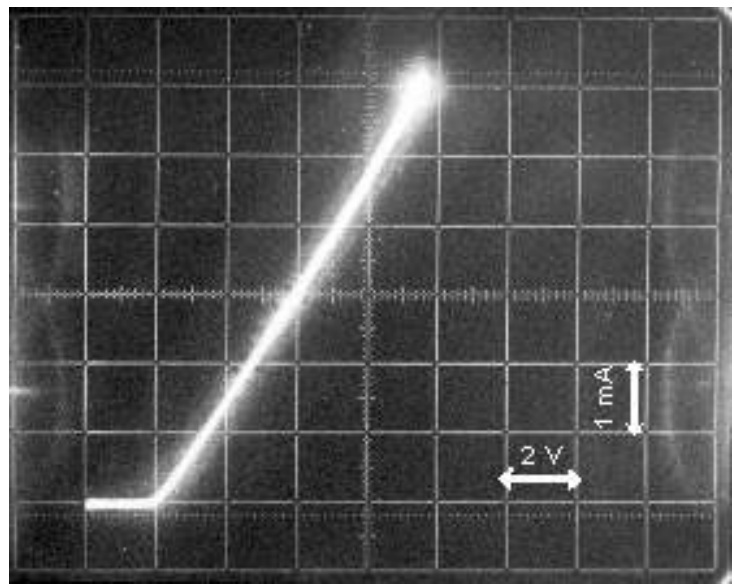

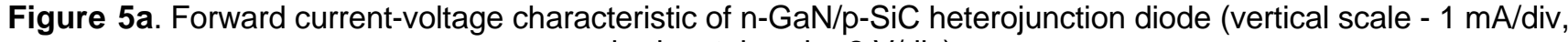
horizontal scale- $2 \mathrm{~V} / \mathrm{div}$ ).

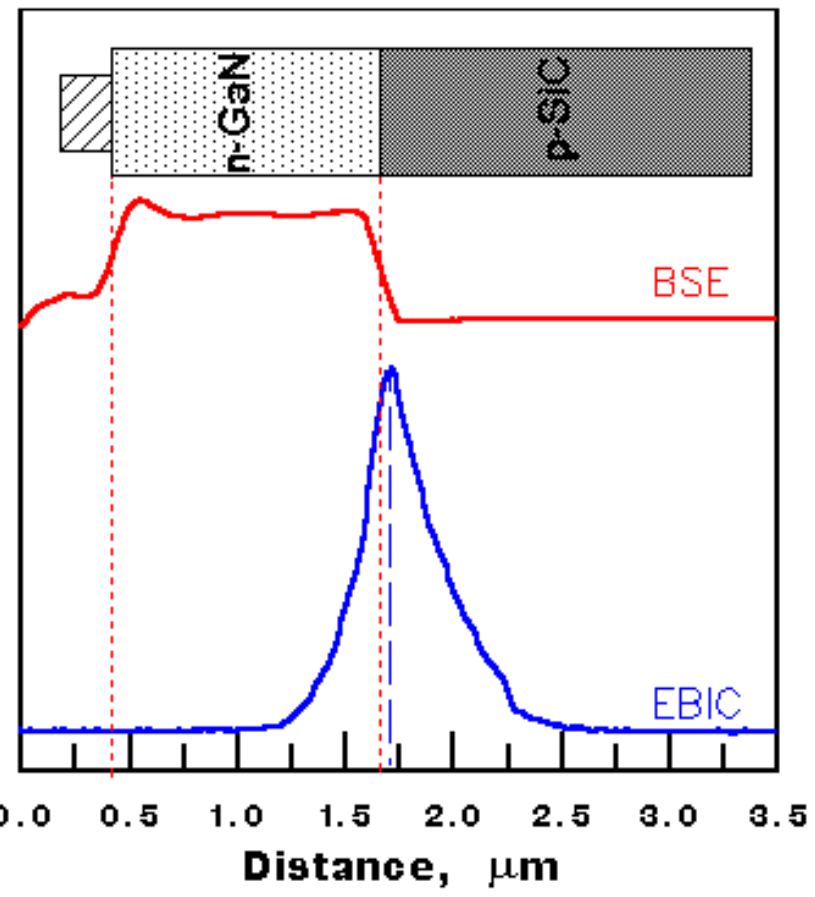

Figure 6. Schematic cross-section drawing for n-GaN/p-SiC heterojunction diode and EBIC/BSE signal profiles across the stucture. 


\begin{tabular}{|c|c|c|c|c|}
\hline $\mathrm{M}$ & $\mathrm{R}$ & $S$ & Internet Journal of & Nitride Semiconductor Research \\
\hline
\end{tabular}

